\title{
Psikolojik Danışma ve Rehberlik Yüksek Lisans Öğrencilerinin Bir Grup Lideri Olarak Kendilerine İlişskin Değerlendirmeleri*
}

\section{Psychological Counseling and Guidance Graduate Students' Evaluation of Themselves as a Group Leader}

\author{
Raşit AVCI**, İsmail SANBERK***
}

Öz: Bu çalışmanın amacı, yüksek lisans öğrencilerinin bir grup lideri olarak kendilerine ilişkin değerlendirmelerini incelemektir. Çalışmaya 2015-2016 Eğitim Öğretim Yılında Muğla Sıtkı Koçman Üniversitesi Psikolojik Danışma ve Rehberlik Yüksek Lisans Programı'nda bir ders kapsamında grup psiko-eğitimi gerçekleştiren yedi grup lideri katılmıştır. Araştırmanın verileri yarı yapılandırılmış bir görüşme olan repertuar ağı tekniği ile toplanmıştır. Repertuar ağı ile verilerin toplanabilmesi için öncelikle değerlendirme nesneleri (elementler) araştırmacılar tarafından belirlenmiş ve elementlerin karşılaştırılması yoluyla elementler arasındaki farklılıklar ve benzerlikler ortaya çıkartılmıştır. Son aşamada her bir katılımcının Repertuar ağı yapısı incelenmiş ve elementler arasındaki öklid uzaklığı hesaplanmıştır. Araştırma sonucunda, ilk olarak grup liderliği konusunda üç katılımcının öz değerinin yüksek, üç katılımcının öz değerinin orta düzeyde olduğu ve birinin de düşük olduğu belirlenmiştir. İkinci olarak süpervizörüme göre bir lider olarak ben elementi ile bir grup lideri olarak ben elementine beş katılımcı yakın konumlandırırken iki katılımcı kısmen yakın olarak konumlandırmıştır. Danışanlarıma göre bir lider olarak ben elementlerini bir grup lideri ben elementine de altı katılımcı yakın konumlandırmış, bir katılımcı ise kısmen yakın konumlandırmıştır. Üçüncü olarak katılımcıların altısının gerek mesleğe başladıkları zamana, gerekse derse başladıkları zamana göre mesleki açıdan gelişim kaydettikleri belirlenmiştir. Bir katılımeı da daha az gelişme kaydettiğini bildirmiştir. Son olarak da katılımcıların "bir grup lideri olarak ben" elementinin, ideal grup lideri, ideal olmayan grup lideri, tanıdığım iyi bir grup lideri ve tanıdığım kötü bir grup lideri elementlerine olan uzaklıkları incelenmiştir. Elde edilen bulgular literatür çerçevesinde yorumlanmış ve tartışılmıştır.

Anahtar Kelimeler: Grup lideri, grup uygulamaları, grup psiko-eğitimi, kendini değerlendirme, repertuar ağı tekniği

Abstract: The purpose of the current study is to investigate the evaluation of the graduate students about
themselves as a group leader. The study group of the current research is composed of seven group leaders
who conducted group psycho-education practices within the context of a course at Psychological
Counseling and Guidance Graduate Program in Mugla Sitk Koçman University in 2015-2016 academic
year. The data of the current study were collected by means of the repertory grid technique, one of the
semi-structured interview techniques. In order to collect data through the repertory grid technique, first,
the objects (elements) to be evaluated were determined by the researchers and similarities and differences
between the elements were elicited through comparison. In the last stage, repertory grid of each
participant was examined and the Euclidean distance was calculated. As a result of the study, firstly it was
found that the eigenvalue of three participants was high; the eigenvalue of three participants was medium
and the eigenvalue of one participant was low. Secondly, while five of the participants located themselves
close the elements "me as a group leader" and "my supervisor as a group leader", two of the participants
located themselves partially close. While six of the participants located themselves to the "me as a group
leader" element, one participant located himself/herself partially close to "my clients as a group leader.

\footnotetext{
* Bu çalışma, 1-3 Aralık 2016 tarihlerinde Gaziantep’te düzenlenen "VI. Ulusal PDR Uygulamaları Kongresinde" sözlü bildiri olarak sunulmuştur.

** Doç. Dr., Muğla Sitkı Koçman Üniversitesi, Eğitim Fakültesi Eğitim Bilimleri Bölümü PDR Anabilim Dalı, Muğla, Türkiye, ORCID: 0000-0003-4947-3397, e-posta: rasitavci@ gmail.com

*** Doç. Dr., Çukurova Üniversitesi, Eğitim Fakültesi Eğitim Bilimleri Bölümü PDR Anabilim Dalı, Adana, Türkiye, ORCID: 0000-0002-1941-6503, e-posta: mailsanberk@ gmail.com
}

Gönderi Tarihi: 14.01.2019 - Kabul Tarihi: 06.04.2019 
Thirdly, six of the participants were found to be thinking that their professional competence improved more in comparison to when they first started their professional career and when they started the course. However, one participant stated less progress. Finally, the distances between the element "me as a group leader" and the elements of an ideal group leader, a non-ideal group leader, a good group leader I know and a bad group leader I know were investigated. The findings obtained were interpreted and discussed in relation to the literature.

Keywords: Group leader, group practices, group psycho-education, self-evaluation, repertory grid technique

\section{Giriş}

Okul psikolojik danışma ve rehberlik uygulamalarında, grup uygulamaları birey ile yapılan uygulamalara göre biraz daha öne çıkmaktadır. Grup uygulamaları, bireyle gerçekleştirilen psikolojik danışma ve rehberlik uygulamalarına göre, pek çok avantajı beraberinde getirmesi sebebiyle bir tercih nedenidir. Örneğin bireysel danışma uygulamalarında yaklaşık 40 dakikalık süre içerisinde bir kişiyle danışma yapma firsatı var iken, grup çalışmalarında bu süre zarfında, grup türüne göre değişmekle birlikte, gruptaki üye sayıs1 kadar bireyle görüşme firsatı mevcuttur. Grup çalışmalarında üye sayısı kadar çözüm yolu olması, grupta öğrenilenlerin günlük yaşama daha kolay aktarılması ve grup üyelerinin bu süreçte kendilerini yalnız hissetmemeleri gibi avantajlar mevcuttur (Voltan-Acar, 2012). Grup ile grubun ait olma, paylaşım duygusu, yeni davranışları uygulama şansı, geri bildirim olanağı, grup üyelerini model alma, gerçek yaşama benzerlik gibi avantajları nedeniyle okullarda gerçekleştirilen çalışmalarda grup yönelimli çalışmaları kullanma bir tercih nedeni olmaktadır (Masson, Jacobs, Harvill ve Schimmel, 2014).

Kapsamlı rehberlik programları çerçevesinde, öğrencilerin acil durumlarının da ihmal edilmemesi koşuluyla, okul danışmanlarının koruyucu ve önleyici boyut çerçevesinde, amaçlı, kapsamlı ve planlı çalışmaların düzenlenerek öğrencilere yönelik çalışmaların yürütülmesini amaçlamaktadır. Yürütülen bu çalışmaların sadece sorunlu öğrencilere değil aynı zamanda tüm öğrencilere yönelik olarak gerçekleştirilmesini amaçlamaktadır. Okul psikolojik danışmanlarının bu hizmetleri tüm öğrencilere ulaştırmaları için grup çalışmaları planlamak ve uygulamak psikolojik danışma ve rehberlik faaliyetlerinin vazgeçilmez bir parçası haline gelmektedir (Sink, Edvwards ve Eppler, 2012). Ancak okul psikolojik danışmanlarının gruplarla çalışmaları yürütebilmeleri için bireysel gerçekleştirilen çalışmalara göre bazı ek bilgi ve becerilere sahip olmaları gerekmektedir. Psikolojik danışmanlar açısından öncelikle bireysel danı̧̧ma becerilerinin öğrenilmesi ve daha sonrasında grup uygulamalarına geçilmesi, aynı anda daha çok grup üyesini takip etme ve etkili tepkileri gösterme gibi becerilerin kazanılması grup liderleri için kaygı verici olduğu da görülmektedir (Ohrt, Ener, Porter ve Young, 2014). Williams, McMahon, Mcleod ve Rice (2013) da benzer şekilde grup çalışmalarını yürüten okul psikolojik danışmanlarında bile, grubu yönetme konusunda korku ve kaygı duyguları yaşadıklarını bildirmektedirler. Benzer şekilde bir başka çalışmada da grup liderlerinin grup yönetme konusunda sıkıntılar yaşadıklarını belirtmektedirler (Güçray, Çekici ve Çolakkığlu, 2009).

$\mathrm{Bu}$ nedenle psikolojik danışman eğitimlerinde, eğitimi alan aday psikolojik danışmanlarının grup çalışmaları konusunda beceri geliştirmeleri de önemli hale gelmektedir. Özellikle liderlerin uzman kişiler tarafından verilen eğitimlerden geçmeleri gerekmektedir (Koydemir, 2013a). Eğer grup liderleri grubu yönetme ve ilerletme konularında gerekli bilgi ve becerilere sahip olmazlarsa, grup üyeleri üzerinde olumuz bir takım sonuçlara neden olabilmektedirler (Türküm ve Akdoğan, 2016). Masson, Jacobs, Harvill ve Schimmel (2014) grup üyelerine yönelik ortaya çıkabilecek olumsuz sonuçlardan dolayı liderin sorumlu olduğunu belirtmektedir. Bu çerçevede, grup lideri adaylarının psikolojik danışma ve rehberlik alanında lisansüstü düzeyde aldıkları eğitimin ve süpervizyon çalışmalarının önemi bir kat daha artmaktadır. Doğal olarak da bu konuda gerçekleştirilen çalışmaların da bu eğitimlerin niteliğini arttırma konusunda katkı sağlayacağı düşünülmektedir. 
Grup liderinin eğitimlerinin niteliğini arttırabilmek için öncelikle grup liderinin grup yönetiminde hangi özelliklere sahip olması gerektiğini belirlemek önem taşımaktadır. Bu konuda çeşitli araştırmacıların farklı sınıflamalarının olduğu göze çarpmaktadır. $\mathrm{Bu}$ sinıflamaları yapan önemli yazarlardan bir olan Yalom (1992) grup liderlerinin danışanlara ilgili, içten, kabullenici ve empatik bir şekilde davranması gerektiğini belirtmektedir. Bir başka araştırmacıya göre de etkili bir liderin görevlerinin de esneklik, açıklık, objektiflik, güvenirlik, dürüstlük ve güç, sabır, duyarlık gibi özellikler yer almaktadır (Corey, Corey ve Corey, 2009). Mason ve diğerlerine (2014) göre, başarılı bir grup yönetmede liderin sahip olması gereken özellikler kişilerle deneyim, gruplarla deneyim, planlama ve organize etme becerileri, konu bilgisi, temel insan çatışmalarını ve ikilemlerini iyi anlama ve danışma kuramları hakkında yeterli bilgi sahibi olma olarak tanımlamıştır. Grup liderlerinin liderlik işlevleri açısından bakıldığında da bu özellikler grup türüne göre farklı rolleri ve fonksiyonları gösterebilmektedirler (Masson ve diğerleri, 2014).

Brown (1994) grup liderinin sahip olduğu özellikleri biraz daha kapsamlı bir şekilde tanımlamakta ve iki kategoride incelemektedir. Bunlardan ilki öğrenme ile kazanılabilen aktif dinleme, yüzleştirme, özetleme, açıklama gibi grupla psikolojik danışma becerilerini içerirken; diğeri de öğrenerek kazanmanın daha az olası olduğu sıcaklık, yakından ilgilenme, kendini ve başkalarını kabul, dürüstlük ve danışmanın içsel konuşmalarını ve tutumlarını içeren inançlar gibi bazı lider özelliklerini içermektedir. Grubun işleyişini kolaylaştıran beceriler genellikle ikinci olarak belirtilen bilişsel olmayan özelliklerden gelişmektedir (Brown, 1994). Özellikle uygulamalar üzerinde doğrudan etkisi olduğu düşünülen bu kişisel özelliklerin belirlenmesi, anlaşılması ve bu özelliklerin gelişimi için danışman adaylarının desteklenmesi, etkili bir grup lideri olmak açısından önemlidir.

Her grup lideri gruba kendi ve başkalarıyla ilişkili dünyayı algılayış şekli ve deneyimleri gibi birtakım kişisel özelliklerini taşır (Gladding, 1995). Bu bağlamda "grup liderinin kendisine ben kimim?", "Seninle birlikte iken kimim?", "Biz birlikteyken kimiz?" gibi soruları kendine sorması gerektiğini belirtmektedir (Hulse-Killacky, 1994; akt: Gladding, 1995). Liderin kişisel özelliklerinin, danışmanların mesleki kimliklerine yani grup liderliğine nasıl dönüştürüldügünün yukarıdaki sorular çerçevesinde anlaş1labilir. Örneğin bir grup lideri güçlü bir benlik duygusuna sahip değil ise, bir grup lideri olarak etkili olacağı şüphelidir (Gladding, 1995). Grup liderlerinin grubu yönetme konusunda kendilerini algılayış biçimleri grup sürecini ve grubun iyileştirici dinamiklerinin harekete geçmesi üzerinde etkili olacağı söylenebilir.

Liderin kişisel gelişimi grup üyeleriyle aralarında yaşanacak olası karşıt-aktarım durumlarını ortadan kaldırabilmekte, becerilerinin gelişmesine, oturumlarda ne yapılması gerektiğinin bilinip anlaşılmasına, danışanların problemlerinin daha iyi anlaşılmasına ve grup üyelerinin problemleriyle başa çıkmada liderin kendine güvenmesini sağlamaktadır (Brown, 2013). Özellikle bu sürecin kendini tanımak ile başladığını belirtmektedir (Brown, 2013). Dolayısıyla grup liderlerinin mesleki ve akademik anlamda kendilerini algılayış biçimlerinin grup süreci üzerinde etkili olabileceği ifade edilebilir. Yukarıda belirtildiği gibi bu özellikler karşıt aktarımın yaşanması ya da liderin kendi özelliklerine ve becerilerine daha az güvenerek uygun tepkileri vermede sıkıntılar yaşaması şeklinde ortaya çıkabilen davranışlar yoluyla gruptaki uyumu bozabilir ve terapötik ilişki miktarında düşüş ortaya çıkarabilir. Bu nedenle grup liderlerinin yüksek lisans eğitimlerini sürdürdükleri ve grup lideri olma konusunda yeni bilgi ve beceriler kazandıkları süreçte kendilerine ilişkin değerlendirmelerini incelemek önem taşımaktadır.

Öte yandan Türkiye'de grup liderliği becerilerini anlamaya ve geliştirmeye yönelik özgün bilimsel çalışmaların sınırlı olduğu görülmektedir (Aladağ, Kağnıcı, Çankaya, ÖzekeKocabaş ve Yaka, 2011; Büyükgöze Kavas, 2011; Pamukçu ve Kağnıcı, 2017a, 2017b). Ayrıca bu çalışmaların biri dışında (Büyükgöze Kavas, 2011), diğerlerinin psikolojik danışma ve rehberlik lisans programında eğitim gören öğrenciler ile gerçekleştirildiği görülmektedir. Bu çalışmanın lisansüstü düzeydeki öğrenim gören öğrencilerin süpervizyon ihtiyaçlarının belirlenmesi ve anlaşılması açısından önemli olduğu belirtilebilir. Dolayısıyla araştırma sonucunda elde edilecek bulguların hem kuramsal açıdan literatüre hem de grup liderlerine 
verilecek süpervizyon uygulamalarında dersi yürüten öğretim elemanlarına, psikolojik danışma alanında çalışan süpervizörlere ve uygulamacılara katkı sağlayacağı düşünülmektedir.

Tüm bu bilgiler ışığında, bu çalışmanın genel amacı, grupla psikolojik danışma uygulamaları dersini alan öğrencilerin bir grup lideri olarak kendilerine ilişkin değerlendirmelerini incelemektir. Bu genel amaç doğrultusunda aşağıdaki şu sorulara yanıt aranmıştır.

1. PDR yüksek lisans öğrencilerinin bir grup lideri olarak öz-değerleri nasıldır?

2. PDR yüksek lisans öğrencilerinin bir grup lideri olarak öz algıları, sosyal benleri ile ne derece örtüşmektedir?

3. PDR yüksek lisans öğrencileri bir grup lideri olarak mesleki gelişimlerini nasıl değerlendirmektedir?

4. PDR yüksek lisans öğrencileri bir grup lideri olarak kendilerini ideal bir grup lideri olmaktan ne denli uzak görmektedir?

\section{Yöntem}

\section{Araştırma deseni}

$\mathrm{Bu}$ araştırma, hipotez test etmeye dönük tek vaka veya olgu analizi modelinde tasarlanmıştır. Hipotezlerin sınandığı olgu çalışmalarında, her bir bireyin belirli bir özelliği veya davranış kalıpları test edilmektedir; ancak her bir olgu için yapılan sınama kendi içerisinde değerlendirilmektedir (Bortz ve Döring, 2013).Vaka analizi çalışması, bir evrene istatistiksel genellemeler yapmak yerine analitik genellemeler yaparak kuramsal önermelerde bulunmay1 hedeflemektedir (Yıldırım ve Şimşek, 2003).

\section{Çalışma grubu}

Bu araştırmanın çalışma grubu, 2015-2016 Eğitim Öğretim Yılın Bahar Döneminde Muğla Sıtkı Koçman Üniversitesi PDR Yüksek Lisans Programı kapsamında yürütülen bir ders kapsamında derse devam eden yedi grup liderinden oluşmuştur. Grup liderlerinin üçü erkek, dördü kadın, yaş aralıkları 22-28 arasında değişmekte olup yaş ortalamaları da 24,43'dür. Grup liderlerinin deneyim yılları ise, $1-5$ yıl arasında değişmekte ve ortalama 2.57 yıllık deneyime sahip oldukları belirlenmiş̧ir. Çalışmada yer alan katılımcıların yaşları ve deneyim yılları şu şekildedir: BG [Kadın, (K)] 25 yaşında ve üçüncü yılı; EY [Erkek, (E)] 28 yaşında ve beşinci yılı; MT(E) 25 yaşında ve üçüncü yılı; NT(K) 25 yaşında ve üçüncü yılı; KA(K) 23 yaşında ve birinci y1lı, FT(K) 23 yaşında ve birinci yılı; AA(E) 24 yaşında ve ikinci yılındadır. Çalışma grubuna bu uygulama, Bahar dönemi sonunda yüksek lisans dersinin notlandırma işleminin tamamlanmasından sonra gerçekleştirilmiştir.

\section{Veri toplama araçları}

Veriler yarı yapılandırılmış bir görüşme olan repertuar ağ tekniği ile toplanmıştır. Repertuar ağ tekniği ile kişilerin belli bir nesne, kişi veya olayla ilgili örtük bilgileri açı̆̆a çıkartılabilmektedir. Repertuar ağında iki temel öğeden biri olan elementler nesne, kişi veya olayı temsil ederken; ikinci temel öğe olan kişisel yapılar bu elementlerin karşılaştırılması yoluyla elde edilmektedir. Repertuar ağı tekniğinin esas alındığı bir çalışma temelde üç işlem basamağından oluşmaktadır. Bu işlem basamakları sırasıyla;

a. Elementlerin belirlenmesi,

b. Elementlerin karşılaştırılması yoluyla kişisel yapıların elde edilmesi,

c. Her bir elementin ortaya çıkartılan kişisel yapılar açısından derecelendirilmesi (Fromm, 2004).

$\mathrm{Bu}$ çalışma kapsamında repertuar ağında yer alacak değerlendirme nesneleri (elementler) araştırmacılar tarafindan öncelikle belirlenmiştir (Bkz. Tablo 1 sütun). Üçlü karşılaştırma yoluyla elementler arasındaki benzerlik ve farklılıklar ortaya konmuştur (Bkz. Tablo 1 satır). Tablo 1 incelendiğinde, ilk satırda gelecekte olmayı arzuladığım grup lideri ve ideal grup lideri elementleri "sakin" kişisel yapısı açısından birbirine benzetilmiş ve tanıdığım kötü bir grup lideri elementinden farklı (gergin) görülmüsstür. En nihayetinde her bir element, 
katılımcıların başvurdukları kişisel yapı çiftleri (örneğin; sakin-gergin vb.) açısından 1 ila 5 arasında derecelendirilmiştir.

Tablo 1.

Örnek Bir Repertuar A $\breve{g}_{1}$

\begin{tabular}{cccccccccccc}
\hline Benzerlik & 1 & 2 & 3 & 4 & 5 & 6 & 7 & 8 & 9 & 10 & Karş1tlik \\
\hline Sakin & & $\mathrm{x}$ & & & & & $\mathrm{x}$ & & & $\mathrm{o}$ & $\begin{array}{c}\text { Gergin } \\
\text { Bilgisiz }\end{array}$ \\
$\begin{array}{c}\text { Özgüvenli } \\
\text { vb. }\end{array}$ & $\mathrm{x}$ & & & $\mathrm{o}$ & $\mathrm{x}$ & $\mathrm{x}$ & & & & & $\begin{array}{c}\text { Bügili } \\
\text { vbensiz }\end{array}$ \\
\end{tabular}

*(1) Bir grup lideri olarak ben, (2) Gelecekte olmayı arzuladı̆̆ım grup lideri, (3) Süpervizörüme göre bir grup lideri olarak ben, (4) Danışanlarıma göre bir grup lideri olarak ben, (5) Mesleğe ilk başladığımda bir grup lideri olarak ben, (6) Grupla psikolojik danışma uygulamaları dersinden önce bir grup lideri olarak ben, (7) İdeal bir grup lideri, (8) İdeal olmayan bir grup lideri, (9) Tanıdığım iyi bir grup lideri ve (10) Tanıdığım kötü bir grup lideri.

\section{Verilerin analizi}

Çalışma grubunda yer alan her bir katılımcının repertuar ağı yapısı incelenmiş ve elementler arasındaki öklid uzaklığı hesaplanmıştır. Veriler, repertuar ağı analizine özgü olarak geliştirilmiş bir istatistiksel yazılım programı olan Idiogrid 2.3 (Grice, 2004) ile çözümlenmiştir.

\section{Bulgular}

Bu çalışmanın ilk araştırma sorusu olan PDR yüksek lisans öğrencilerinin bir grup lideri olarak öz-değerleri, "Bir grup lideri olarak ben" elementi ile "gelecekte olmayı arzuladığım grup lideri" elementleri arasındaki uzaklık katsayısının hesaplanması ile tespit edilebilmektedir. Buna göre güncel ben ve ideal ben arasındaki uzaklığın 0.68 değerinden küçük bir değer göstermesi bireyin öz-değerinin veya benlik saygısının yüksek olduğuna işaret etmektedir. Öz-değeri orta düzeyde olanlarda, bu iki element arasındaki uzaklık 0.68 ila 1.07 arasındadır. Uzaklık katsayısının 1.07'den daha yüksek bir değer göstermesi ise öz-değerin düşük olduğuna işaret etmektedir (Bartholomew, 1993). PDR yüksek lisans öğrencilerinin bir grup lideri olarak öz değerlerine ilişkin elde edilen bulgular aşağıda Tablo 1'de sunulmuştur.

Tablo 2.

Bir Grup Lideri Olarak Ben Elementi ile "Gelecekte Olmayı Arzuladığım Grup Lideri” Elementleri Arasındaki Öklid Uzaklık Katsayıları

\begin{tabular}{lc}
\hline Olgu & $\begin{array}{c}\text { Gelecekte olmay } \\
\text { arzuladı̆̆ım grup lideri }\end{array}$ \\
\hline AA & 0.69 \\
BG & 0.70 \\
EY & 0.50 \\
FT & 0.71 \\
KA & 1.25 \\
MT & 0.50 \\
NT & 0.64 \\
\hline
\end{tabular}

Tablo 2 incelendiğinde katılımcıların üçünün öz-değeri yüksek, üçünün orta ve birinin düşük olduğu görülmektedir. Buna göre EY, MT ve NT adlı katılımcıların öz-değeri yüksek (< 0.68); AA, BG ve FT adlı katılımcıların öz-değeri orta olarak hesaplanmıştır $(0.68-.71)$. Bir grup lideri olarak sadece katılımc1 KA'nın öz-değeri düşük (> 1.07) olarak gözlenmiştir. Bu çalışmanın ikinci araştırma sorusu olan PDR yüksek lisans öğrencilerinin bir grup lideri olarak kendilerini, sosyal benlerini temsil eden "Süpervizörüme göre bir grup lideri olarak ben" ile "Danışanlarıma göre bir grup lideri olarak ben" elementlerine ne denli uzak gördüğüne ilişkin 
bulgular Tablo 3'de sunulmuştur. Bir grup lideri olarak ben elementi ile bu iki element arasındaki uzaklık katsayısı ne denli düşük olması, katılımcının kendisini "süpervizör ve danışanların gözünden ben" ile aynı doğrultuda görüyor olduğuna işaret etmektedir. Diğer bir ifadeyle "güncel ben" ile "sosyal ben" tutarlı bir şekilde görüldüğü anlamına gelmektedir.

Tablo 3.

Bir Grup Lideri Olarak Ben Elementinin "Süpervizörüme ve Danışanlarıma Göre Bir Grup Lideri Olarak Ben" Elementlerine Olan Öklid Uzaklığı

\begin{tabular}{lcc}
\hline Olgu & $\begin{array}{c}\text { Süpervizörüme göre bir lider } \\
\text { olarak ben }\end{array}$ & Danışanlarıma göre bir lider olarak ben \\
\hline AA & 0.33 & 0.37 \\
BG & 0.67 & 0.57 \\
EY & 0.41 & 0.29 \\
FT & 0.56 & 0.51 \\
KA & 0.29 & 0.50 \\
MT & 0.63 & 0.50 \\
NT & 0.33 & 0.44 \\
\hline
\end{tabular}

Tablo 3'deki öklid uzaklık katsayıları incelendiğinde, katılımcıların bir grup lideri olarak kendilerine ilişkin değerlendirmeleri, her iki sosyal ben elementi ile tutarlık göstermektedir. "Bir grup lideri olarak ben" elementini "Süpervizörüme göre bir grup lideri olarak ben" elementine en yakın konumlandıran katılımcı KA olmuştur $(\mathrm{d}=.29)$. KA'yı, .33 uzaklık katsayısı değeri ile AA ve NT takip etmiştir. Bu katılımcıları sırasıyla EY $(\mathrm{d}=.41)$, FT $(\mathrm{d}=.56)$, MT $(\mathrm{d}=.63)$ ve $\mathrm{BG}(\mathrm{d}=.67)$ takip etmiştir. Özellikle MT ve BG adlı katılımcıların bir grup lideri olarak kendilerine yönelik algılarının, süpervizörlerinin onlara ilişkin algıları ile kısmen farklılaştığı söylenebilir.

"Bir grup lideri olarak ben" elementini "Danışanlarıma göre bir grup lideri olarak ben" elementine en yakın konumlandıran katılımcı EY olmuştur $(\mathrm{d}=.29)$. EY'i, .37 uzaklık katsayısı değeri ile AA ve .44 uzaklık katsayısı değeri ile NT takip etmiştir. Bu katılımcıları .50 uzaklık katsayısı değeri ile KA ve MT; .51 uzaklık katsayısı değeri ile FT takip etmiştir. Özellikle BG adlı katılımcının bir grup lideri olarak kendisine yönelik algısı, danışanlarının ona ilişkin algısı ile kısmen farklılaştığı söylenebilir. Bu çalışmanın üçüncü araştırma sorusu doğrultusunda elde edilen bulgular, PDR yüksek lisans öğrencilerinin bir grup lideri olarak kendilerini, "Mesleğe ilk başladığımda bir grup lideri olarak ben" ve "Grupla psikolojik danışma uygulamaları dersinden önce bir grup lideri olarak ben" elementlerine ne denli uzak görüyor olduğuna ilişkindir. Uzaklık katsayısının yüksek bir değer göstermesi çok fazla gelişme olduğuna ilişkin bir bilgi içermektedir. Örneğin bu değerin 1'e yakın veya üstünde bir değer göstermesi, mevcut ben ile geçmişteki ben arasında oldukça fazla bir farkın (veya gelişmenin) olduğu anlamına gelmektedir.

Tablo 4.

Bir Grup Lideri Olarak Ben Elementinin Mesleğe İlk Başladığımda ve Uygulama Dersinden Önce "Bir Grup Lideri Ben" Elementlerine Olan Öklid Uzaklığ1

\begin{tabular}{lcc}
\hline Olgu & $\begin{array}{c}\text { Mesleğe ilk başladığımda lider } \\
\text { olarak ben }\end{array}$ & $\begin{array}{c}\text { Bu ders öncesinde bir lider olarak } \\
\text { ben }\end{array}$ \\
\hline AA & 0.55 & 0.44 \\
BG & 0.76 & 0.61 \\
EY & 0.64 & 0.52 \\
FT & 0.42 & 0.37 \\
KA & 0.25 & 0.20 \\
MT & 0.76 & 0.99 \\
NT & 0.49 & 0.36 \\
\hline
\end{tabular}


Tablo 4 incelendiğinde bir grup lideri olarak, mesleğe ilk başladığından bu yana kendinde en büyük gelişmeyi gözlemleyen kişi BG ve MT olmuştur $(\mathrm{d}=.76)$. Kendinde görece en az gelişme gözlemleyen katılımcı KA olmuştur $(\mathrm{d}=.25)$. Mesleğe ilk başladığından bu yana çok baskın olmasa da bir grup lideri olarak EY $(\mathrm{d}=.64)$, AA $(\mathrm{d}=.55), \mathrm{NT}(\mathrm{d}=.49)$ ve FT $(\mathrm{d}=$ .42) kendilerinde bir gelişme gözlemlemişlerdir.

Grupla psikolojik danışma uygulamaları dersinden sonra kendinde belirgin bir şekilde gelişme gözlemleyen katılımcı MT olmuştur $(\mathrm{d}=.99)$. Bu katılımcıyı, .61 uzaklık katsayısı değeri ile BG ve .52 uzaklık katsayısı değeri ile EY olmuştur. Ders sonrası kendinde görece en az gözlemleyen kişi KA olmuştur $(\mathrm{d}=.20)$. Bunu sırasıyla NT $(\mathrm{d}=.36)$, FT $(\mathrm{d}=.37)$ ve AA $(\mathrm{d}$ $=.44$ ) takip etmiştir. Bu çalışmanın son araştırma sorusu doğrultusunda elde edilen bulgular, PDR yüksek lisans öğrencilerinin bir grup lideri olarak kendilerini, "İdeal bir grup lideri”, "İdeal olmayan bir grup lideri”, "Tanıdığım iyi bir grup lideri" ve "Tanıdığım kötü bir grup lideri” elementlerine ne denli uzak görüyor olduğuna ilişkindir.

Tablo 5.

Bir Grup Lideri Olarak Ben Elementinin İdeal Bir Grup Lideri Doğrultusundaki Elementlere Olan Öklid Uzaklığ 1

\begin{tabular}{lcccc}
\hline Olgu & İdeal bir grup lideri & $\begin{array}{c}\text { İdeal olmayan bir } \\
\text { grup lideri }\end{array}$ & $\begin{array}{c}\text { Tanıdı̆̆ım iyi bir } \\
\text { grup lideri }\end{array}$ & $\begin{array}{c}\text { Tanıdığım kötü bir } \\
\text { grup lideri }\end{array}$ \\
\hline AA & 0.88 & 1.46 & 0.60 & 0.82 \\
BG & 0.62 & 1.31 & 0.74 & 1.31 \\
EY & 0.76 & 1.31 & 0.55 & 1.27 \\
FT & 0.63 & 1.33 & 0.58 & 1.27 \\
KA & 1.32 & 0.86 & 1.13 & 0.86 \\
MT & 0.50 & 1.41 & 0.50 & 1.28 \\
NT & 0.64 & 1.29 & 0.66 & 1.21 \\
\hline
\end{tabular}

Tablo 5 incelendiğinde, bir grup lideri olarak kendini "ideal bir grup lideri" elementine en yakın konumlandıran kişi MT olmuştur $(\mathrm{d}=.50)$. Buna karşın bu elementten en uzak konumlandıran kişi KA olmuştur $(\mathrm{d}=1.32)$. Benzer bir şekilde "tanıdı̆̆ım iyi bir grup lideri" elementine kendini en yakın konumlandıran kişi yine MT olmuştur $(\mathrm{d}=.50)$. KA ise kendini bu elementten en uzak konumlandıran kişi olmuştur $(\mathrm{d}=1.13)$. Bir grup lideri olarak kendini "ideal olmayan bir grup lideri olarak ben" elementinden en uzak konumlandıran katılımeı AA ( $d=$ 1.46) ve MT ( $=1.41)$ olmuştur. Diğer katılımcılarla karşılaştırıldığında KA kendini bu elemente nispeten yakın konumlandırmıştır $(\mathrm{d}=.86)$. Benzer bir şekilde KA adlı katılımeı kendini $(\mathrm{d}=.86)$ AA ile birlikte $(\mathrm{d}=.82)$ "tanıdığım kötü bir grup lideri" elementine yakın konumlandırmıştır. Tanıdığım kötü bir grup lideri elementine kendini en uzak konumlandıran kişi $\mathrm{BG}$ olmuştur $(\mathrm{d}=1.31)$.

\section{Tartışma / Sonuç ve Öneriler}

Bu çalışmada psikolojik danışma ve rehberlik alanında yüksek lisans düzeyinde yürütülen bir ders kapsamında, yüksek lisans öğrencilerinin bir grup lideri olarak kendilerine ilişkin değerlendirmeleri incelenmiştir. Bu kapsamda elde edilen ilk bulgu "Bir grup lideri olarak ben" ve "gelecekte olmayı arzuladığım grup lideri" arasındaki mesafe incelenmiş bu derse katılan öğrencilerin altısının uygulamalar konusunda üçünün öz değerleri yüksek, üçünün öz değeri orta bir katılımcının ise öz değerinin düşük olduğu görülmektedir. Burada ifade edilen öz değer, yüksek lisans öğrencilerinin kendilerini mesleki anlamda nasıl algıladıkları ile ilgilidir. Mesleki bağlamda açıklanan bu kavram bir grup lideri olarak yetkin olarak hissetmeyle ilişkilendirilebilir. Grup çalışmalarında yetkinlik birçok elementi içerisinde barındıran geniş bir kavramdır. Yetkinlik en basit tanımıyla meslek elemanının alanında uzmanlaşmış olmasını ifade 
etmektedir (Gizir, 2013). Bu tanım çerçevesinde düşünüldüğünde grup lideri adayının alanıyla ilgili mesleki açıdan gerekli bilgi ve beceriye sahip olması şeklinde değerlendirilebilir. Dolayısıyla yüksek lisans öğrencileri biri dışında hepsinin kendilerini mesleki açıdan psikoeğitim gruplarını yürütme konusunda yeterli gördükleri ifade edilebilir. Bu sonuç grup lideri adaylarının süpervizyon sürecinde aldıkları geribildirimlerin ve grup liderliği ile ilgili yaşadıkları kaygılarını yönetebilmelerinin aday okul psikolojik danışmanlarının grup liderliği öz yeterliklerini olumlu yönde yordadığını bildiren çalışmalarla tutarlık göstermektedir (Daniels ve Larson, 2001; Springer, 2016). Bu çalışmada da ders kapsamında uygulamalar tamamlandıktan sonra, yüksek lisans öğrencilerinin grup psiko-eğitim çalışmalarını yürütmede kendilerini büyük ölçüde yetkin algıladıkları görülmektedir. Ancak unutulmaması gereken bir nokta ise, yetkinliğin ulaşılan bir zirve olmayıp, grup çalışmacılarının eğitime, profesyonel süpervizyona ve hem kişisel hem de profesyonel gelişim aktivitelerini katılma gibi çalışmalar aracılığıyla bilgi ve beceri yeterliklerini arttırmalarının (Çivitci, 2018; Thomas ve Pender, 2008) önemli olduğunu gözden kaçırmamalılardır.

Grup lideri ve grup lideri adaylarının kendilerini algılama biçimleri bir psikolojik danışman olarak kendilerinden memnun olmaları mesleği uygulamaları açısından oldukça önem taşımaktadır. Koydemir (2013b) psikolojik danışma gruplarında grup lideri adaylarının yeni teknik ve becerileri uygulama konusunda ikilem yaşadıklarını, zaman zaman hata yapabildiklerini ve bu tip durumlarda da özgüvenlerinin azaldığını belirtmektedirler. Bu durum yüksek lisans öğrencilerin mesleki açıdan benlik algılarını yapılandırma sürecinde olduklarını gösterebilir. Bu çalışmada, grup liderlerinden $\mathrm{KA}(\mathrm{K})$ 'nın kendisine ilişkin öz değerinin düşük olduğu saptanmıştır ve KA(K)'nın da mesleki benlik algısını yapılandırma sürecinde olduğu söylenebilir. Grup lideri adaylarının süreç içerisinde kendilerine ilişkin beklentilerinin yüksek olması ve bu beklentilerinin karşılanmaması sonucunda mesleki açıdan kendilerini yetersiz hissettiği düşünülebilir. Dryden ve Reeves (2014) psikolojik danışmanların hissetmiş oldukları yetersizlik duygularının psikolojik danışmanlar üzerinde zaman zaman olumlu sonuçları da ortaya çıkarabildiğini belirtmektedirler. Bu çıktıların psikolojik danışmanın oturumlara daha iyi odaklanmasını ve istekli olmasını ve psikolojik danışma sürecinde psikolojik danışmanın kullandığ 1 tarzı ve stratejileri değiştirmesini sağlayabileceğini ifade etmektedir. Benzer şekilde psikolojik danışmanların psikolojik danışma sürecine ilişkin öğrenmeye yönelik davranışlarının da artmasına örneğin; okuma davranışlarının artmasına, arkadaşlarından geribildirim almalarına, psikolojik danışma süreci konusundaki eğitimlere katılma ve süpervizyon alma gibi konularda ek çaba göstermelerine yardımcı olabileceği de belirtilmektedir (Dryden ve Reeves, 2014). Sonuç olarak danışmanların mesleki açıdan kendilerini yetersiz algılamalarının da tamamen olumsuz olmadığı değerlendirilebilir. $\mathrm{Bu}$ durumun bazı olumlu çıtıtları da olabileceği görülmektedir.

Bu çalışmanın ikinci bulgusu, "süpervizörüme göre bir lider olarak ben" bir grup lideri olarak gerçek benine en yakın konumlandıran sırasıyla KA(K), AA(E), NT(K), EY(E)'dir. MT (E) ve $B G(K)$ 'nin algılarının bundan kısmen farklılaştığı görülmektedir. Bu bulgulardan elde edilen sonuç katılımcıların kendilerini algılamalarıyla süpervizörün onları bir grup lideri olarak algılamalarının önemli ölçüde örtüştüğü, MT(E) ve BG(K)'nin bakış açılarında kısmen örtüşmediği şeklinde değerlendirilebilir. Bu kapsamda sorulan diğer soru ise, bir grup lideri olarak ben elementini, danışanlarıma göre bir lider olarak ben elementini yakın konumlandıran, $\mathrm{EY}(\mathrm{E}), \mathrm{AA}(\mathrm{E}), \mathrm{NT}(\mathrm{K}), \mathrm{KA}(\mathrm{K}), \mathrm{MT}(\mathrm{E})$, ve $\mathrm{FT}(\mathrm{K})$ takip etmiştir. $\mathrm{BG}(\mathrm{K})$ 'nin danışanlarıma göre bir lider olarak ben elementinin danışanlarının algısına göre kısmen farklılaştığ 1 değerlendirilebilir. Sonuçlar genel olarak süpervizörüme ve danışanlarıma göre grup lideri olarak benlerinin gerçek benleri ile örtüştügünü göstermektedir.

Ancak bu noktada dikkat edilmesi gereken, $\mathrm{KA}(\mathrm{K})$ 'nın kendisine ilişkin öz değerinin düşük olduğu, bu nedenle bu değerlendirmenin örtüşmesinin süpervizörüme göre bir grup lideri olarak ben ile tutarlı olduğudur. $\mathrm{Bu}$ kapsamda $\mathrm{KA}(\mathrm{K})$ araştırmanın birinci sorusu ile de tutarlı bir şekilde, kendisini dış kaynaklara göre de negatif değerlendirdiği anlaşılmaktadır. Diğer katılımcıların ise, öz değerlerinin olumlu bağlamda yüksek olduğu değerlendirilebilir. Benlik saygısına baktığımızda özellikle yaşamdaki geçiş aşamalarında dalgalanmalar görüldüğü ve bu 
geçiş aşamalarında benlik değerinin düştüğü görülmektedir (Galambos, Barker ve Krahn, 2006). $\mathrm{KA}(\mathrm{K})$ 'nın mesleğini ilk yılında olması, bir geçiş aşamasında olduğunu göstermekte ve aynı zamanda okulda da psikolojik danışman olarak çalışmaktadır. Bu çerçevede mesleki uyum sürecinde grup lideri olarak da bir öz değerinde bir dalgalanma olduğu ve benlik saygisının da düştüğü değerlendirilebilir. Bununla birlikte, benlik saygısının düşüklüğü, başarısızlık duygusunu ve kendini eleştirme davranışlarını ortaya çıkararak birtakım uyum sorunlarıyla da ilişkili olabilmektedir (Fennel, 2009). Dolayısıyla süpervizyon sürecinde katılımcıların mesleki becerileriyle olduğu kadar kendilerini algılama biçimleri ile de ilgilenmek yerinde olabilir.

Benlik kavramının oluşumunda önemli öğelerden biri başkalarının gözünden nasıl göründüğümüzün değerlendirilmesidir. $\mathrm{Bu}$ çerçevede katılımcıların grup liderliğine ilişkin mesleki benlik algılarını onların grup liderliği ile ilgili yaşantıların tanık olan iki kaynağa (süpervizör ve grup üyeleri) göre değerlendirmeleri istenmiştir. Bireyin diğerleri tarafından nasıl görüldügüne ilişkin inançlarına ayna benlik adı verilmektedir (Santrock, 2014). Katılımcıların önemli oranda bir grup lideri olarak kendilerini pozitif gördükleri yönünde inançları olduğu görülmektedir. Büyükgöze Kavas (2011) geçekleştirdiği çalışmada, yüksek lisans ve doktora öğrencilerinin süpervizyon çalışmalarının daha verimli geçebilmesi için süpervizörlerin olumlu yönlerde de geri bildirim vermeleri ve destekleyici olmalarının önemli olduğunu belirtmiştir. $\mathrm{Bu}$ çerçevede süpervizyon sürecinde verilen geribildirimlerin önemli olduğu, yapıcı ve destekleyici geribildirimlerin olumlu benlik yapısının oluşmasına yardımcı olacağı söylenebilir.

Araştırmanın üçüncü sorusundan elde edilen bir diğer bulgu ise "grup lideri ben" elementiyle, mesleğe ilk başladığımda lider olarak ben ve bu ders öncesinden bir lider olarak ben elementleri açısından her iki soruda altı katılımcının mesleki gelişim bakımından ilerleme kaydettikleri görülmektedir. Her iki soru açısından da en az gelişmeyi KA(K)'nın gösterdiği belirlenmiştir. $\mathrm{Bu}$ bulgu, katılımcıların hem meslek hayatında çalışmalarının ve deneyim kazanmalarının hem de yüksek lisans eğitimine katılarak uygulamalar yapmalarının onların mesleki gelişimlerinde önemli bir rol oynadığı söylenebilir. Bu kapsamda öz değeri diğer katılımcılara göre daha olumsuz olan KA(K)'da mesleki gelişim açısından az da olsa ilerleme kaydettiğini göstermektedir. Mesleki gelişim, bu noktada Bandura'nın (1977) öz yeterlik kavramı ile ilişkilendirilebilir. Bandura (1977) kişinin öz yeterliğinin gelişmesi için (a) doğrudan yaşantıların; (b) dolaylı yaşantıların; (c) sözel iknanın (uzman görüşü) ve (d) kişinin psikolojik durumunun bu kavram üzerinde etkili olduğu görülmektedir. Grup liderlerinin yukarıda belirtilen açıklamalar doğrultusunda, katılımcıların gerek iş yaşamında gerekse grup psiko-eğitim uygulaması sırasında uygulama yapmalarının ve yine ders sirasında uygulama yapan diğer katılımcıları görmelerinin grup liderliği ile ilgili öz yeterliklerinin gelişmesinde rol oynadığı ifade edilebilir. Ek olarak Atıcı, Sanberk ve Ortakale (2011) psikolojik danışman adaylarının grup düzeninde deneyim yaşamalarının da onların mesleki ve kişisel gelişimlerine katk1 sağladığını belirtmektedirler. Özellikle süpervizyon süreciyle ilgili ifade edilecek olursa, Delucia-waack (1999) etkili bir grup lideri olmak için, yeni bilgilere ulaşmayı öğrenmenin de önemli olduğunu ve bu kaynakların ise, okumalar, videoların, konferansa katılımların ve akran ile süpervizörlerden geri bildirim almak olduğunu belirtmektedir. $\mathrm{Bu}$ çerçeve araştırma bulguları mevcut literatür ile tutarlık göstermektedir.

$\mathrm{Bu}$ araştırmanın dördüncü sorusunda bir grup lideri olarak ben ile ideal bir grup lideri, ideal olmayan bir grup lideri, tanıdığım iyi bir grup lideri, tanıdığım kötü bir grup lideri elementleriyle yakınlık ve uzaklık değerleri hesaplanmıştır. Bu kapsamda elde edilen sonuçlar katılımcıların ideal grup lideri elementine yakın olarak konumlandırması bir grup lideri olarak kendilerinin öz saygılarının yüksek olduğu, uzak konumlandırmaları durumunda da düşük olduğu değerlendirilebilir. Bu hipotezden elde edilen sonuçlar diğer hipotezlerden elde edilen sonuçlarla tutarlı olduğu, bu noktada ideal bir grup lideri olarak ben elementine kendini uzak olarak konumlandıran $\mathrm{KA}(\mathrm{K})$ 'nın, tanıdığım iyi bir grup liderine uzak, ideal olmayan grup liderine ve tanıdığım kötü bir grup liderine yakın konumlandırmıştır. Bu çerçevede bu dört hipotezden elde edilen bulguların tutarlı olduğu görülmektedir.

Mesleğe yeni başlayan grup liderlerinin öz saygıları yüksek olabildiği kadar düşük de olabilmektedir. Grup liderliği konusundaki dersleri uygulayan süpervizörlerin öğrencilerin grup 
lideri olarak öz saygıları ile çalışması, kendilerini daha gerçekçi değerlendirmesi konusunda yardımc1 olması gerekli olabilir. Grup liderlerinin, ideal olan meslek elemanıyla ilgili beklentilerinin mükemmel ile ilişkilendirilmesi ve bilişsel açıdan bir takım çarpıtmaların olması kendini bu şekilde değerlendirmesinde önemli bir değişken olabilir. Bu bağlamda süpervizyon uygulamalarının grup liderlerinin sadece becerilerine yönelik değil aynı zamanda mesleki açıdan kendilerini algılamalarına yönelik çalışmalara da ihtiyaç duyulduğu anlaşılmaktadır.

Diğer taraftan ideal benlik içerisinde olmak istediğimiz yöndeki özelliklerimiz kadar, olmak istemediğimiz, olmaktan korktuğumuz yönlerimiz de mevcuttur. Quinlan, Jaccard ve Blanton (2006) bu kavramı olası benlik olarak adlandırmaktadır. İdeal bir grup lideri olmayı istedikleri, ideal olmayan grup lideri de olmayı istemedikleri olmaktan kaçındıkları grup liderini vurgulamaktadır. Olası benlik çerçevesinden değerlendirildiğinde, katılımcıların ideal olan ve olmayan grup liderine göre kendilerini konumlandırmaları önemlidir. İdeal grup liderinin davranışlarının betimlenmesi ve bu yönde davranışlarda bulunulması, ideal olmayan grup liderinin betimlenmesi istenmeyen davranışların betimlenilerek bu davranışlardan kaçınılması söz konusudur. Bu bağlamda tanıdığım iyi bir grup lideri ve tanıdığım kötü bir grup lideri de benzer şekilde olası benlik çerçevesinde değerlendirilebilir. İyi grup lideri davranışları olası benliğin olmak istenen davranış özelliklerinin belirlenerek bu yönde çaba gösterilmesi, tanıdığım kötü bir grup lideri de olunmak istenmeyen grup liderini betimlemektedir. Süpervizyon açısından danışmanların olası benlikleri ile çalışılması, yapılması beklenen davranışlar kadar beklenmeyen davranışların da betimlenmesi ve süpervizyon alan psikolojik danışmanlarla ve öğrencilerle bunun değerlendirilmesi onların gelişimlerine katkı sağlayabilir. Özellikle olası benliğin bireyin geleceğe yönelik bakış açılarının netleşmesini sağlama, amaçlar geliştirmesini sağlama ve bu şekilde bu amaçlara ulaşmak için atılacak davranışsal adımları belirlenme gibi işlevleri olduğu düşünüldüğünde (Aydın, 1996), psikolojik danışmanların ya da danışman adaylarının mesleki anlamda motivasyon oluşturmalarına yardımcı olabilir. Grup liderliğine yönelik motivasyonel davranışların neler olabileceği değerlendirildiğinde ise, yeni bilgilere ulaşmayı öğrenmek ve bu kaynakların ise, okumalar, videoların, konferansa katılımların ve akran ile süpervizörlerden geri bildirim almak şeklindedir (Delucia-waack, 1999).

Bulgular, bir ders kapsamında kazandırılması hedeflenen yeterliklere ulaşılıp ulaşılmadığının testinde repertuar ağı tekniğinin kullanılabileceğini göstermektedir. Aynı şekilde psikolojik danışmanların "ideal veya etkili bir psikolojik danışman" ile ilgili bilişsel temsilleri bu yolla sinanabilir (Sanberk, 2016). Grup liderliği becerilerini geliştirmeye yönelik uygulama derslerinin hedeflerinden biri, uzman adayı danışmanların bir grup lideri olarak kendilerini daha yetkin görmelerine yardımcı olmaktır. Nitekim elde edilen bulgular danışmanların bu özgül mesleki etkinlikle ilgili öz değerlendirmelerinin eğitim süreci içerisinde iyileştiğini göstermektedir.

Pek çok çalışmada olduğu gibi bu çalışmanın da bir takım sınırlılıkları vardır. Öncelikle yüksek lisansta yürütülen ders öncesinde grup liderlerinin kendilerine ilişkin algıları değerlendirilemediği için gerçekten ortaya çıkan verilerin derste yürütülen uygulamaların etkisiyle ortaya çıkıp çıkmadığı bilinememektedir. Bu nedenle gelecekte gerçekleştirilecek çalışmalarda ön test uygulaması da gerçekleştirilerek dersin etkisi ile ilgili değerlendirmede bulunulabilir. Ayrıca grup liderlerinin algılarının kendi bakış açılarıyla belirlenmesi ve ders katılımında akran ve hoca değerlendirmelerine yer verilmemesi de bir sinırlılık olarak göze çarpmaktadır. Bu bağlamda gelecekte yapılacak çalışmalarda grup liderlerinin algılarının yanı sıra akran değerlendirmesi ya da süpervizörlerin görüşleri de alınarak daha kapsamlı değerlendirme yapılabilir. Bu çalışmanın sınırlılıklarından biri de danışman adaylarının deneyim sürelerinin az olmasıdır. Bu çalışma daha uzun deneyim süresine sahip grup liderleri ile de gerçekleştirilebilir.

\section{Kaynaklar}


Aladağ, M., Kağnıcı, D. Y., Çankaya, Z. C., Özeke Kocabaş, E. ve Yaka, B. (2011). Psikolojik danışman eğitiminde grupla çalışma yeterliklerinin kazandırılması: Ege Üniversitesi örneği. Ege Ĕ̆itim Dergisi, 2(12), 22-43.

Atıc1, M., Sanberk, İ. ve Ortakale, M. Y. (2011). Mesleki ve kişisel gelişim açısından PDR üçüncü sınıf öğrencilerinin grup rehberliği etkinliklerine ilişkin görüşlerinin incelenmesi. Çukurova Üniversitesi Sosyal Bilimler Enstitüsü Dergisi, 20(3), 459-474.

Aydın, B. (1996). Benlik kavramı ve ben şemaları. M.Ü. Atatürk Ĕgitim Fakültesi Eğitim Bilimleri Dergisi, 8, 41-47.

Bandura, A. (1977). Self-efficacy: Toward a unifying theory of behavioral change. Psychological Review, 84, 191-215. doi:10.1037/0033-295X.84.2.191

Bartholomew, U. (1993). Die Selbst-Identitäts-Graphik [The self-identity graphic]. Einführung in Die Repertory Grid-Technik, 2, 30-37.

Bortz, J. ve Döring, N. (2013). Forschungsmethoden und Evaluation: Für Human-und Sozialwissenschaftler. Springer-Verlag.

Brown, N. W. (1994). Group counseling for elementary and middle school children. USA: Praeger Publishers.

Brown, N. W. (2013). Psikolojik danışmanlar için psiko-eğitsel gruplar: Hazırlama ve uygulama rehberi. V. Yorğun (Çev.). Ankara: Anı Yayıncılık.

Büyükgöze Kavas, A. (2011). Bireysel ve grupla psikolojik danışma uygulamalarına yönelik bir değerlendirme. Türk Ĕ̈itim Bilimleri Dergisi, 9(2), 411-432.

Corey, M. S., Corey, G. ve Corey, C. (2009). Groups: Process and practices (Eighth Edition). F. Aysan, S. Balcı Çelik ve A. Uz Baş (Çev. edt.). Ankara: Nobel Akademik Yayıncılık.

Çivitci, A. (2018). Grup psikoeğitimi. Ankara: Pegem Akademi.

Daniels, J. A. ve Larson, L. M. (2001). The impact of performance feedback on counseling selfefficacy and counselor anxiety. Counselor Education and Supervision, 41, 120-130.

DeLucia-Waack, J. L. (1999). What makes an effective group leader? Journal for Specialists in Group Work, 24(2), 131-132. 132, doi: 10.1080/01933929908411424

Dryden, W. ve Reeves, A. (2014). Psikolojik danışma uygulamalarında temel konular. F. Akkoyun (Çev.). Ankara: Nobel Akademik Yayıncılık

Fennel, M. J. (2009). Overcoming low self-esteem: A self-help guideusing Cognitive Behavioral Techniques. London: Constable \& Robinson Ltd.

Fromm, M. (2004). Introduction to the repertory grid interview. Waxmann Verlag.

Galambos, N. L., Barker, E. T. ve Krahn, H. J. (2006). Depression, self-esteem, and anger in emerging adulthood: Seven-year trajectories. Developmental psychology, 42(2), 350.

Gizir, C. A. (2013). Grupla psikolojik danışma ve etik. A. Demir ve S. Koydemir (Yay. haz.). Grupla Psikolojik Danışma içinde (ss.73-88). Ankara: Pegem Akademi.

Gladding, S.T. (1995). Group Work: A counseling specialty. New Jersey: Merrill Prentice Hall.

Grice, J. W. (2004). Idiogrid: Idiographic analysis with repertory grids (Version 2.3). Stillwater, Oaklahoma.

Güçray, S. S., Çekici, F. ve Çolakkadığlu, O. (2009). Psiko-eğitim gruplarının yapılandırılması ve genel ilkeleri. Mersin Üniversitesi Ĕ̈itim Fakültesi Dergisi, 5(1), 134-153.

Koydemir, S. (2013a). Grubun doğası ve yapısı. A. Demir ve S. Koydemir (Yay. haz.). Grupla psikolojik danışma içinde (ss.1-24). Ankara: PegemAkademi.

Koydemir, S. (2013b). Psikolojik danışma gruplarında lider becerileri. A. Demir ve S. Koydemir (Yay. haz.), Grupla psikolojik danışma içinde (s.225-250). Ankara: Pegem Akademi.

Masson, R. L., Jacops E. E., Harvill, R. L. ve Schimmel, S. J. (2014). Group counseling intervention and techniques (çev. P. Nedim Bal). Ankara: Pegem Akademi.

Ohrt, J. H., Ener, E., Porter, J. ve Young, T. L. (2014). Group leader reflections on their training and experience: Implications for group counselor educators and supervisors. The Journal for Specialists in Group Work, 39, 95-124. doi:10.1080/01933922.2014. 883004 
Quinlan, S. L., Jaccard, J. ve Blanton, H. (2006). A decision theoretic and prototype conceptualization of possible selves: Implications for the prediction of risk behavior. Journal of Personality, 74(2), 599-630.

Pamukçu, B. ve Kağnıcı, D. Y. (2017a). Turkish counselor trainees' experiences regarding experiential groups: A qualitative study. Journal of Human Sciences, 14(1), 560-570.

Pamukçu, B. ve Kağnıcı, D. Y. (2017b). Beceriye dayalı grupla psikolojik danışma eğitiminin grupla psikolojik danışma becerilerine etkisinin incelenmesi. Elektronik Sosyal Bilimler Dergisi, 16(61), 448-465.

Sanberk, İ. (2016). Investigation and classification of personal constructs representing ideal counselor from insider perspective. Journal of Education and Training Studies, 4(8), $56-64$.

Santrock, J. W. (2014). Ergenlik. D. M. Siyez (Çev.). Ankara: Nobel Akademik Yayıncılık.

Sink, C. A., Edwards, C. N. ve Eppler, C. (2012). School based group counseling. Belmont, CA: Brooks/Cole Cengage Learning.

Springer, S. I. (2016) Examining predictors of group leader self-efficacy for preservice school counselors. The Journal for Specialists In Group Work, 41(4), 286-311, doi: 10.1080 /01933922.2016.1228723

Thomas, R. V. ve Pender, D. A. (2008). Association for specialists in group work: Best practice guidelines 2007 revisions. The Journal for Specialists in Group Work, 33(23), 111-117, doi: 10.1080/01933920801971184

Türküm, S. ve Akdoğan, R. (2016). Grupla psikolojik danışmada bir profesyonel ve bir birey olarak lider. Türk Psikolojik Danışma ve Rehberlik Dergisi, 3(27), 123-137.

Voltan-Acar, N. (2012). Grupla psikolojik danışma: Ilke ve teknikleri. Ankara: Nobel Yayın Dağıtım.

Williams, C. U., McMahon, H. G., McLeod, A. L. ve Rice, R. (2013). An exploration of secondary school counselors' experiences engaging in group work, The Journal for Specialists in Group Work, 38(2), 96-120, doi: 10.1080/01933922.2013.775205

Yalom, I. D. (1992). The theory and practice of group psychotherapy. New-York: Basic Books.

Yıldırım, A. ve Şimşek, H. (2006). Sosyal bilimlerde nitel araştırma yöntemleri. Ankara: Seçkin Yayıncilık.

\section{Extended Abstract}

\section{Introduction}

In the psychological counseling training, it is important for candidate counselors receiving training to develop their skills needed for group practices. Particularly leaders should undergo trainings offered by experts (Koydemir, 2013a). If group leaders do not have the necessary knowledge and skills in managing and advancing the group, they may lead to emergence of some negative outcomes for group members (Türküm \& Akdoğan, 2016). Masson, Jacobs, Harvill and Schimmel (2014) emphasize that the leader is responsible for negative consequences experienced by group members. In this regard, the importance of the training and supervision practices of group leader candidates at the graduate level in the field of psychological counseling and guidance is increasing. Naturally, it is thought that the studies carried out in this subject will contribute to increasing the quality of these trainings. For this reason, during the process in which group leaders continue their graduate studies and acquiring new knowledge and skills in the way of becoming a group leader, investigating their evaluations of themselves is of importance in terms of identifying the difficulties encountered by them during this process and developing the outcomes of this process.

The purpose of the current study is to investigate the evaluations of the graduate students taking the course group practices about themselves as a group leader. To this end, answers to the following questions were sought:

1- What are the eigenvalues of psychological counseling and guidance (PCG) graduate students as a group leader? 
2- To what extent do self-perceptions of the PCG graduate students as a group leader comply with their social-self?

3- How do the PCG graduate students evaluate their professional development as a group leader?

4- How distant do the PCR graduate students see themselves as a group leader from being an ideal group leader?

\section{Method}

\section{Research design}

The current study was designed in the single case or phenomenon analysis model directed at testing a hypothesis. In the phenomenological studies in which hypotheses are tested, a particular feature or behavioral patterns of each individual are tested; however, the testing performed for each phenomenon should be evaluated in itself (Bortz \& Döring, 2013). A case analysis research aims to come up with theoretical propositions by making analytical generalizations rather than making statistical generalizations for a population (Yıldırım \& Şimşek, 2003).

\section{Study group}

The study group of the current research is comprised of seven group leaders enrolled in the course of group practices within the context of the Psychological Counseling and Guidance Graduate Program in Muğla S1tk1 Koçman University in 2015-2016 academic year. Three of the participants are males and four are females; their ages are in the range of 22-28, with an average of 24.43. The length of participants' experience as a group leader varies between 1 and 5 years, with an average of 2.57 .

\section{Data collection tools}

The data of the current study were collected through the repertory grid technique. In order to collect data through the repertory grid technique, first the objects (elements) to be evaluated were determined by the researchers.

The 10 elements to be evaluated in the current study are as follows: (1) Me as a group leader, (2) The group leader I want to be in the future, (3) Me as a group leader in comparison to my supervisor, (4) Me as a group leader according to my clients, (5) Me as a group leader when I started the profession first, (6) Me as a group leader before the course of group psychological counseling practices, (7) An ideal group leader, (8) A non-ideal group leader, (9) A good group leader I know and (10) A bad group leader I know.

\section{Data analysis}

The repertory grid structure of each participant in the study group was examined and the Euclidean distance between the elements was calculated. The data were analyzed by using Idiogrid 2.3 (Grice), which is a statistical software specially developed for repertory grid analysis.

\section{Result and Discussion}

The current study examined the self-evaluations of graduate students taking the course Group Practices in the field of psychological counseling and guidance. In this context, first the distance between "Me as a group leader" and "The group leader I want to be in the future" and the eigenvalue of the three of the students was found to be high, the eigenvalue of another three students was found to be medium and the eigenvalue of one of them was found to be low. The eigenvalue is an indication of how the graduate students perceive their professional development. This concept can be related to the extent to which the students as a group leader feel confident. 
The second finding of the current study is that five participants closely located the element "me as a group leader" to the elements "me as a group leader in comparison to my supervisor". Two participants' perceptions are a bit different from this. Another question asked in this context revealed that five of the participants located the element "me as a group leader" to the element "me as a leader in comparison to my advisor". As a result, it can be argued that the element "me as a group leader" overlaps the element "me as a group leader in comparison to my supervisor and advisor" to a great extent.

Another finding obtained for the third question of the study is that six of the participants think that they made a progress in terms of the element "me as a group leader" when compared to the elements "me as a group leader when I first started the profession" and "me as a group leader before I started to take this course. Only one participant thinks that he/she made little progress. Thus, it can be argued that as a result of their having more practice in their professional lives and doing some practices during their graduate education, they feel professionally more developed. One of the participants with lower eigenvalue seems to have made little progress when compared to the others.

Within the context of the fourth question, proximity and distance values between the element "me as a group leader" and the elements "an ideal group leader", "a non-ideal group leader", "a good group leader I know", "a bad group leader I know". In this context, the students' locating themselves close to the element of "an ideal group leader" shows that their self-esteem as a group leader is high while their locating themselves distant to the element "an ideal group leader" shows that their self-esteem as a group leader is low. The results obtained from this hypothesis comply with the results obtained from the other hypotheses; in this regard, one participant locating himself/herself distant to the element "a good group leader I know" also located himself/herself close to the elements "a non-ideal group leader" and "a bad group leader I know". In this context, the findings obtained for these four hypotheses seem to be concurring.

One of the objectives of the course of group practices is to help graduate students in psychological counseling and guidance feel more confident as a group leader. The findings of the current study show that the students' self-evaluations of their professional competence improved during the course. 